\title{
Effects of piperonyl butoxide on the toxicity of the organophosphate temephos and the role of esterases in the insecticide resistance of Aedes aegypti
}

\author{
Boscolli Barbosa Pereira ${ }^{[1]}$, Jean Ezequiel Limongi ${ }^{[1]}$, Edimar Olegário de Campos Júnior ${ }^{[2]}$, \\ Denis Prudencio Luiz ${ }^{[2]}$ and Warwick Estevam Kerr ${ }^{[2]}$
}

[1]. Departamento de Saúde Ambiental, Universidade Federal de Uberlândia, Uberlândia, MG. [2]. Departamento de Genética e Bioquímica, Universidade Federal de Uberlândia, Uberlândia, MG.

\begin{abstract}
Introduction: The effects of piperonyl butoxide (PBO) on the toxicity of the organophosphate temephos (TE) and the role of esterases in the resistance of Aedes aegypti to this insecticide were evaluated. Methods: A. aegypti L4 larvae susceptible and resistant to TE were pre-treated with PBO solutions in acetone at concentrations of $0.125,0.25,0.5,1$, and $2 \%$ for $24 \mathrm{~h}$ and subsequently exposed to a diagnostic concentration of $0.02 \mathrm{mg} / \mathrm{L}$ aqueous TE solution. The esterase activity of the larvae extracts pre-treated with varying PBO concentrations and exposed to TE for three time periods was determined. Results: At concentrations of $0.25,0.5,1$, and $2 \%$, PBO showed a significant synergistic effect with TE toxicity. High levels of esterase activity were associated with the survival of $A$. aegypti L4 larvae exposed to TE only. Conclusions: The results of the biochemical assays suggest that PBO has a significant inhibitory effect on the total esterase activity in A. aegypti larvae.
\end{abstract}

Keywords: Temephos. Insecticide resistance. Aedes aegypti. Esterases.

\section{INTRODUCTION}

Dengue fever, a major viral disease, is a serious public health problem, especially in tropical countries where the climate and urban culture provide optimal conditions for the development and proliferation of its main vector, the mosquito Aedes aegypti ${ }^{1}$.

The control of $A$. aegypti is primarily based on the use of chemical and biological products that are integrated with environmental management programs. Public programs aimed at controlling mosquitoes are characterized by the use of commercial insecticides, including organophosphates and pyrethroids. The organophosphate temephos (TE) was widely used in Brazil to control A. aegypti larvae until recently; however, due to reports of vector resistance to this insecticide, this method was replaced by the National Dengue Control Program. Nevertheless, TE remains on the list of insecticides to control dengue in Brazil and may be used again in the future ${ }^{2,3}$.

The resistance to insecticides has contributed to an increase in A. aegypti populations and the incidence of dengue cases in Asia, and Central and South America, especially in Brazil ${ }^{2,4}$.
The biochemical mechanisms involved in the development of resistance to insecticides include detoxification metabolism processes. Several enzymes and enzyme systems participate in these processes, including oxidases, esterases, and transferases ${ }^{5}$. These enzymes allow the insect to convert an insecticide to a nontoxic form or to rapidly eliminate the compound from the body.

Synergists such as piperonyl butoxide (PBO) have been employed in an attempt to overcome resistance to insecticides. Synergists are known to act as an alternative substrate, competing with the insecticide and interfering with detoxification. Synergists also act allosterically to inhibit the binding sites of esterases and multifunction oxidases (MFOs), minimizing the amount of insecticide needed to control insects and the levels of environmental contamination by pesticide residues ${ }^{6}$.

Several studies have demonstrated the successful use of synergists for insect control through their inhibitory action on esterase activity and MFOs in resistant strain ${ }^{7,8}$; however, studies investigating their action in A. aegypti are rare. The aim of the present study was to evaluate the effects of $\mathrm{PBO}$ on the toxicity of the organophosphate pesticide TE and the involvement of esterases in the resistance of $A$. aegypti to this compound.

\section{METHODS}

Address to: Dr. Boscolli Barbosa Pereira. Dept de Saúde Ambiental/UFU. Av. João Naves de Ávila 2121, 38400-902 Uberlândia, MG, Brasil.

Phone: 5534 3291-5989; Fax: 5534 3291-4169

e-mail: boscolli86@hotmail.com; boscolli@ig.ufu.br

Received 19 August 2014

Accepted 15 October 2014

\section{Samples}

Aedes aegypti-susceptible and -resistant strain samples were provided by the Center for Zoonosis Control of Uberlândia (CZCU). The research was conducted by studying 
natural resistant populations of $A$. aegypti collected in five neighborhoods with high rates of vector infestation according to the Health Department of Uberlândia. The Rockefeller population, maintained for ten generations in the laboratory, was used as the susceptible population of reference. L4 larvae were used in the experiments as recommended by the World Health Organization?.

\section{Aedes aegypti strains}

To confirm resistance in the strains, the larvae were submitted to a diagnostic dose of $0.012 \mathrm{mg} / 1$ of TE, according to standardized methodology recommended by the World Health Organization ${ }^{10}$. When the mortality rate was higher than $98 \%$, the population was considered susceptible. Populations that showed mortality rates of 80 to $98 \%$ underwent repeat testing for confirmation, and populations in which the mortality rates were equal to or lower than $80 \%$ were considered resistant.

\section{Pretreatment with $\mathrm{PBO}$ and TE exposure}

Susceptible and resistant L4 larvae were pre-treated with PBO diluted in acetone at concentrations of $0.125,0.25,0.5,1$, and $2 \%$ for $24 \mathrm{~h}$. For each test, 10 groups of 10 larvae were placed in Petri dishes with $40 \mathrm{ml}$ of $0.02 \mathrm{mg} / 1$ aqueous TE solution, while the control groups were placed in $40 \mathrm{ml}$ of water only. The larval mortality was assessed following $2 \mathrm{~h}$ of exposure according to the procedure by Bezzerra et $\mathrm{al}^{4}$.

\section{Esterase activity}

The esterase activity of the larvae extracts pretreated with PBO and exposed to TE for three exposure times (30, 60, and 120min) was determined using $\alpha$-naphthyl acetate as the substrate in microtiter plates, according to the technique developed by Devonshire ${ }^{11}$ with modifications by Pruett et $\mathrm{al}^{12}$. The protein content was estimated in triplicate using Bradford's method (Bradford, 1976) ${ }^{13}$ with bovine serum albumin as the standard.

The living larvae were centrifuged $\left(4^{\circ} \mathrm{C}, 15,000 \times \mathrm{g}, 15\right.$ $\mathrm{min}$ ) with $100 \mathrm{ml}$ of extraction buffer $(20 \mathrm{mM}$ sodium phosphate, $\mathrm{pH}$ 7.0). The obtained supernatant was collected and diluted 1:50 in extraction buffer. The diluted $50 \mu 1$ samples were incubated with $150 \mu 1$ of extraction buffer containing $0.5 \mathrm{mM} \alpha$-naphthyl acetate for $30 \mathrm{~min}$ at $30^{\circ} \mathrm{C}$ in darkness.
Fifty microliters of extraction buffer containing $0.15 \%$ o-dianizidina and $1.75 \%$ sodium dodecyl sulfate were added. The optical density values were measured in an enzyme-linked immunosorbent assay (ELISA) reader (Titertek Multiskan Plus MKII, Flow Laboratories, McLean, VA, USA) using $450 \mathrm{~nm}$ filters and converted to micromoles of naphthol per min per $\mathrm{mg}$ of protein $(\mathrm{mmol} / \mathrm{mg} / \mathrm{min}$ protein), according to a standard curve using the Microplate Manager PC v. 4.0 (Bio-Rad Laboratories, Inc., Hercules, CA, USA).

\section{Statistical analysis}

The mortality rates of the susceptible and resistant larvae strains were compared using the Chi-square test of heterogeneity between the populations. An analysis of variance (ANOVA), followed by Tukey's and Kramer HSD tests, were used to compare the rates of esterase activity between the susceptible and resistant strains in different profiles of exposure to the five concentrations of $\mathrm{PBO}$ tested. The differences were considered significant if $\mathrm{p}<0.05$.

\section{RESULTS}

\section{Susceptibility and resistance to temephos: the effects of PBO on the toxicity of TE}

The results of $2 \mathrm{~h}$ exposure to $0.02 \mathrm{mg} / \mathrm{l} \mathrm{TE}$ in the susceptible and resistant strains of $A$. aegypti larvae in the control test (without pre-treatment with PBO) and experimental tests (with pretreatments of different concentrations of $\mathrm{PBO}$ ) are shown in Table 1.

No mortality was observed in the water-only control in either of the studied strains. The larvae of the susceptible strain exposed to the diagnostic dose of $0.012 \mathrm{mg} / 1 \mathrm{TE}$ without pretreatment with PBO showed $98 \%$ mortality, while the mortality of the resistant strain under the same conditions was $51.3 \%$.

The mortality rates in the susceptible larvae pre-treated with varying concentrations of $\mathrm{PBO}$ and exposed to $0.02 \mathrm{mg} / \mathrm{l} \mathrm{TE}$ showed no significant differences compared with the control group. The resistant group larvae with $\mathrm{PBO}$ pre-treatment at concentrations of $0.25,0.5,1$, and $2 \%$ showed a significantly higher mortality $(\mathrm{p}<0.05)$ compared with the resistant control group, with the highest mortality obtained by $1 \%$ PBO pre-treatment.

TABLE 1 - Percent mortality of Aedes aegypti larvae exposed to different concentrations of piperonyl butoxide.

Tests

\begin{tabular}{|c|c|c|c|c|c|c|c|}
\hline & \multicolumn{2}{|c|}{ Controls } & \multicolumn{5}{|c|}{ TE $(0.02 \mathrm{mg} / \mathrm{l})$ after pre-treatment with PBO (\%) } \\
\hline & Water & $\mathrm{TE}(0.02 \mathrm{mg} / \mathrm{l})$ & 0.125 & 0.25 & 0.5 & 1 & 2 \\
\hline Strain & M & M & M & M & M & M & M \\
\hline Resistant & 0 & 51.3 & 52.0 & $67.3^{c}$ & $78.6^{\mathrm{c}}$ & $90.6^{\mathrm{d}}$ & $77.3^{\mathrm{c}}$ \\
\hline
\end{tabular}

PBO: piperonyl butoxide; TE: temephos; M: mortality of larvae (\%). ${ }^{\mathrm{c}}$ Difference at $\mathrm{p}<0.05 .{ }^{\mathrm{d}}$ Difference at $\mathrm{p}<0.01 . \mathrm{n}=140 . \chi^{2}$ test of heterogeneity between the populations. 


\section{Effects of PBO on esterase activity}

The esterase activity in the larvae of the susceptible and resistant strains treated with five concentrations of PBO and the respective control groups treated only with acetone at three exposure times (30, 60, and 120min) are shown in Table 2.

In the control groups, no difference ( $p>0.05)$ was observed in esterase activity in either the susceptible or resistant strain regardless of the exposure time. In the treated groups, esterase activity in the resistant larvae exposed to $0.25,0.5$, and $1 \%$ PBO was significantly lower than in the control group when the exposure time was extended to 60 and $120 \mathrm{~min}(\mathrm{p}<0.05)$. Regarding the susceptible larvae, only 1 and 2\% PBO at both 60 and $120 \mathrm{~min}$ exposure times were associated with significantly reduced esterase activity $(\mathrm{p}<0.05)$.

\section{DISCUSSION}

In insects, organophosphate insecticides are detoxified by enzymes such as carboxylesterase, transferases, and oxidases that act by hydrolysis or by reducing the number of free organophosphate molecules. This detoxification metabolism is probably the most studied mechanism of insect pesticide resistance. Synergists have been employed to overcome resistance in various pests and vectors ${ }^{14-16}$. The present study demonstrated that $0.25,0.5,1$, and $2 \%$ PBO increased the toxicity of TE to a resistant strain of $A$. aegypti larvae, with the maximum effect observed at the $1 \%$ concentration, which was associated with a $39.3 \%$ higher mortality than observed in the control group.

The results of the analysis of the esterase activity in the resistant strains suggest that the synergistic effect of $\mathrm{PBO}$ on the toxicity of TE was, at least partially, due to a decrease in the general esterase activity of these populations. The inhibitory effect of the esterase activity was not shown to be dose- or timedependent in either larval strain. Moreover, as the resistance was not completely overcome, mechanisms in addition to esterase activity may be involved in the resistance of these populations.

The larvae of the resistant strain pretreated with $2 \%$ PBO showed a lower mortality than the strain pretreated with $1 \%$ $\mathrm{PBO}$. This reduction may be explained by an antagonistic effect of $\mathrm{PBO}$, which is likely due to the activation of cytochrome $\mathrm{P} 450$. This activation may have inhibited PBO because cytochrome $\mathrm{P} 450$ enzyme isoforms are known to be responsible for the inhibition of organophosphates and $\mathrm{PBO}^{17}$.

PBO acts as an inhibitor of P450, suppressing the bioactivation of TE and reducing its toxicity. Many arthropod species possess multiple isomers of $\mathrm{P} 450$, and all are substratespecific $^{18}$. In this study, PBO reduced the toxicity of TE but only at the highest concentration tested. Thus, although PBO had no significant effect on the toxicity of TE at a concentration of $0.125 \%$, synergism increased its toxicity at concentrations ranging from $0.25 \%$ to $1 \%$. The effect of $0.5 \%$ and $1 \%$ PBO was higher for the resistant strain but decreased at the $2 \%$ concentration.
TABLE 2 - Esterase activity of susceptible and resistant strains of Aedes aegypti larvae exposed to piperonyl butoxide.

\begin{tabular}{|c|c|c|c|}
\hline \multirow[b]{2}{*}{$\begin{array}{l}\text { Time } \\
(\mathrm{min})\end{array}$} & \multirow[b]{2}{*}{$\begin{array}{c}\text { PBO } \\
(\%)\end{array}$} & \multicolumn{2}{|c|}{ Strain } \\
\hline & & $\begin{array}{c}\text { Resistant } \\
\mathrm{M} \pm \mathrm{SD}^{\mathrm{a}}\{\text { mortality }\}\end{array}$ & $\begin{array}{c}\text { Susceptible } \\
\mathrm{M} \pm \mathrm{SD}^{\mathrm{a}}\{\text { mortality\} }\end{array}$ \\
\hline \multirow[t]{6}{*}{30} & 0 & $339 \pm 164\{0\}$ & $410 \pm 144\{0\}$ \\
\hline & 0.125 & $436 \pm 89\{0\}$ & $402 \pm 67\{0\}$ \\
\hline & 0.25 & $367 \pm 91\{0\}$ & $398 \pm 84\{0\}$ \\
\hline & 0.5 & $353 \pm 51\{0\}$ & $377 \pm 54\{0\}$ \\
\hline & 1 & $337 \pm 77\{0\}$ & $363 \pm 49\{0\}$ \\
\hline & 2 & $331 \pm 62\{1\}$ & $349 \pm 78\{1\}$ \\
\hline \multirow[t]{6}{*}{60} & 0 & $395 \pm 231\{0\}$ & $315 \pm 103\{1\}$ \\
\hline & 0.125 & $321 \pm 87\{0\}$ & $279 \pm 51\{0\}$ \\
\hline & 0.25 & $277 \pm 61^{\mathrm{b}}\{0\}$ & $277 \pm 32\{0\}$ \\
\hline & 0.5 & $281 \pm 36^{\mathrm{b}}\{0\}$ & $201 \pm 90^{\mathrm{b}}\{0\}$ \\
\hline & 1 & $263 \pm 66^{\mathrm{b}}\{1\}$ & $198 \pm 101^{b}\{1\}$ \\
\hline & 2 & $329 \pm 85\{0\}$ & $292 \pm 56\{0\}$ \\
\hline \multirow[t]{6}{*}{120} & 0 & $422 \pm 156\{0\}$ & $424 \pm 129\{0\}$ \\
\hline & 0.125 & $375 \pm 58\{0\}$ & $431 \pm 69\{0\}$ \\
\hline & 0.25 & $310 \pm 53^{\mathrm{b}}\{0\}$ & $375 \pm 71\{0\}$ \\
\hline & 0.5 & $303 \pm 71^{\mathrm{b}}\{2\}$ & $302 \pm 58^{\mathrm{b}}\{0\}$ \\
\hline & 1 & $246 \pm 55^{\mathrm{b}}\{1\}$ & $271 \pm 43^{\mathrm{b}}\{0\}$ \\
\hline & 2 & $355 \pm 96\{0\}$ & $360 \pm 72\{0\}$ \\
\hline
\end{tabular}

PBO: piperonyl butoxide; ${ }^{\mathrm{a}}$ Mean \pm standard deviation $(\mathrm{mmol} / \mathrm{mg} / \mathrm{min}$ protein). ${ }^{b}$ Difference at a significance level of $5 \% . n=10$. Analysis of variance (ANOVA); Tukey-Kramer test.

Resistance based on cytochrome P450 explains the synergistic effect of PBO with TE toxicity at the lower concentrations $(0.25,0.5$, and $1 \%)$ and inhibition at the highest concentration $(2 \%)$.

The differential effects of $\mathrm{PBO}$ on the toxicity of insecticides in resistant strains observed in these studies may be attributed to the inhibitory effects of $\mathrm{PBO}$ to different P450 isomers involved in the activation and detoxification of organophosphate molecules. According to this hypothesis, at $2 \%$, the effects of isomers responsible for the bioactivation of TE increased, offsetting the effect of the isomers involved in metabolic detoxification ${ }^{18-22}$.

For the susceptible strain, pre-treatment with PBO did not confer altered levels of toxicity; therefore, the individuals in this population may express tolerance to the insecticide ${ }^{6}$.

Toxicology assays and investigations of esterases conducted in resistant mosquito strains have indicated that the survivability of these insects is associated with the increased expression of esterases ${ }^{20}$. Similar results have been observed in assays involving other classes of organophosphates ${ }^{22,23}$. 
Effects similar to the findings presented in this study have been found in various assays showing synergism between low concentrations of PBO and organophosphates in insect species $^{14,15,20,24,25}$.

The high level of synergism of $1 \%$ PBO in the larvicidal effect of TE has important implications for the control of A. aegypti larvae. TE formulations with this concentration of PBO may be effective in the control of both susceptible and resistant strains of $A$. aegypti larvae.

\section{CONFLICT OF INTEREST}

The authors declare that there is no conflict of interest.

\section{REFERENCES}

1. Forattini OP. Yellow fever. Rev Saude Publica 1999; 33:534-537.

2. Carvalho MSL, Caldas ED, Degallier N, Vilarinhos PTR, Souza LCKR, Yoshizawa MAC, et al. Susceptibility of Aedes aegypti larvae to the insecticide temephos in the Federal District, Brazil. Rev Saude Publica 2004; 38:623-629.

3. Prophiro JS, Silva OS, Luna JED, Piccoli CF, Kanis LA, Silva MAN. Aedes aegypti and Aedes albopictus (Diptera: Culicidae): coexistence and susceptibility to temephos, in municipalities with occurrence of dengue and differentiated characteristics of urbanization. Rev Soc Bras Med Trop 2011; 44:300-305.

4. Beserra EB, Fernandes CRM, Queiroga MFC, Castro Jr FP. Resistência de populações de Aedes aegypti (L.) (Diptera: Culicidae) ao organofosforado temefós na Paraíba. Neotrop Entomol 2007; 36:303-307.

5. Hemingway J. The molecular basis of two contrasting metabolic mechanisms of insecticide resistance. Insect Biochem Mol Biol 2000; 30:1009-1015.

6. Gunning RV, Moores GD, Devonshire AL. Esterases inhibitors synergise the toxicity of pyrethroids in Australian Helicoverpa armigera (Hubner) (Lepidoptera: Noctuidae). Pest Manag Sci 1999; 63:50-62.

7. Daglish GJ, Eslkema M, Harrison LM. Chlorpyrifosmethyl plus either methoprene or synergized phenothrin for control of Coleoptera in maize in Queensland, Australia. J Stored Prod Res 1995; 31:235-241.

8. Lorini I, Galley DJ. Effect of synergists piperonyl butoxide and DEF in deltamethrin resistance on strains of Rhyzopertha dominica (F.) (Coleoptera: Bostrychidae). An Soc Entomol Bras 2000; 294:749-755.

9. World Health Organization (WHO). Vector resistance to pesticides. Fifteenth report of the WHO Expert Committee on Vector Biology and Control. World Health Organ Tech Rep Ser 1992; 818:61-62.

10. World Health Organization (WHO). Instructions for determining the susceptibility or resistance of mosquito larvae to insecticides. WHO/ VBC/81.807; 1981; p.1-6.

11. Devonshire AL, Moores GD, French-Constant RH. Detection of insecticide resitance by immunological estimation of carboxylesterase activity in Myzus persicae (Sulzer) and cross reaction of the antiserum with Phorodon humuli (Schrank) (Hemiptera: Aphididae). Bull Entomol Res 1986; 76:97-107.

12. Pruett JH, Oeler DD, Kammlah DM, Guerrero FD. Evaluation of horn flies (Diptera: Muscidae) from a pyrethroid susceptible colony for general and permethrin esterase activities. J Econ Entomol 2000; 93:920-924.

13. Bradford M. A rapid and sensitive method for the quantitation of microgram quantities of protein utilizing the principle of protein-dye binding. Anal Biochem 1976; 72:248-254.

14. Beckel HS, Lorini I, Lazzari SMN. Efeito do sinergista butóxido de piperonil na resistência de Oryzaephilus surinamensis (L.) (Coleoptera, Silvanidae) a deltametrina e fenitrotiom. Rev Bras Entomol 2006; 50:110-114.

15. Wilson JA, Clark AG, Haak NA. Effect of piperonyl butoxide on diazinon resistance in field strains of the sheep blowfly, Lucilia cuprina (Diptera: Calliphoridae), in New Zealand. Bull Entomol Res 1999; 89:295-301

16. Young SJ, Gunning RV, Moores GD. The effect of piperonyl butoxide on pyrethroid-resistance-associated esterases in Helicoverpa armigera (Hübner) (Lepidoptera: Noctuidae). Pest Manag Sci 2005; 61:397-401.

17. Scott JG, Wen Z. Cytochromes P450 of insects: the top of the iceberg. Pest Manag Sci 2001; 57:958-967.

18. Li AY, Pruet JH, Davey RB, George JE. Toxicological and biochemical characterization of temephos resistance in the San Roman strain of Boophilus microplus (Acari: Ixodidae). Pestic Biochem Physiol 2005; 81:145-153.

19. Kotze AC, Sales N. Elevated in vitro monooxygenase activity associated with insecticide resistances in field-strain larvae of the Australian sheep blowfly (Diptera: Calliphoridae) J Econ Entomol 1995; 884:782-787.

20. Bisset JA, Marín R, Rodríguez MM, Severson DW, Ricardo Y, French L, et al. Insecticide resistance in two Aedes aegypti (Diptera: Culicidae) strains from Costa Rica. J Med Entomol 2013; 50:352-361.

21. Pisani-Borg E, Cuany A, Burn A, Amichot M, Fournier D, Berge JB. Oxidative degradation of temephos by Drosophila-metabolic changes associated with insecticide resistance and induction. Pestic Biochem Physiol 1996; 54:56-64.

22. Sabourault C, Guzov VM, Koener JF, Claudianos C, Flapp FW, Feyereisen R. Overproduction of a P450 that metabolize OP is linked to a loss-of-function in chromosome 2-aliesterase (MdaE7) gene in resistant house flies. Insect Mol Biol 2001; 10:609-618.

23. Zhou X, Meike LJ, Siegfried BD, Scharf ME, Sarath G, Chandler LD. Partial purification and characterization of a methyl-parathion resistance-associated general esterase in Diabrotica virgifera virgifera (Coleoptera: Chrysomelidae) Pestic Biochem Physiol 2004; 78:114-125.

24. Li AY, Davey RB, Miller RJ, George JE. Resistance to coumaphos and diazinon in Boophilus microplus (Acari: Ixodidae) and evidence for the involvement of an oxidative detoxification mechanism. J Med Entomol $2003 ; 404: 482-490$.

25. Li AY, Guerrero FD, Pruett JH. Invovement of esterases in diazinon resistance and biphasic effects of piperonyl butoxide on diazinon toxixity to Haematobia irritans irritans (Diptera: Muscidae). Pestic Biochem Physiol 2007; 87:147-155. 